\title{
Correction to: International Review on Public and Nonprofit Marketing Volume 16, issue 2-4
}

\section{The Publisher ${ }^{1}$}

Published online: 18 December 2019

(C) Springer-Verlag GmbH Germany, part of Springer Nature 2019

Correction to: International Review on Public and Nonprofit Marketing Volume 16 , issue 2-4

https://doi.org/10.1007/s12208-019-00223-5

https://doi.org/10.1007/s12208-019-00224-4

https://doi.org/10.1007/s12208-019-00225-3

https://doi.org/10.1007/s12208-019-00228-0

https://doi.org/10.1007/s12208-019-00229-z

https://doi.org/10.1007/s12208-019-00230-6

https://doi.org/10.1007/s12208-019-00231-5

https://doi.org/10.1007/s12208-019-00232-4

https://doi.org/10.1007/s12208-019-00233-3

"Unfortunately in Volume 16, the Issue 2-4 had been published online with an incorrect date (2001 instead of 2019).

The publisher regrets this error and the date has been corrected online."

Publisher's Note Springer Nature remains neutral with regard to jurisdictional claims in published maps and institutional affiliations.

The online version of the issue can be found at https://link.springer.com/journal/12208/16/2

The Publisher

Springer-Verlag GmbH, DE, Heidelberger Platz 3, 14197 Berlin, Germany 